\title{
Ayahuasca Ethno-tourism and its Impact on the Indigenous Shuar Community (Ecuador) and Western Participants
}

\author{
Dima Salibová
}

\author{
DOI: 10.21104/CL.2020.4.05
}

\begin{abstract}
An indigenous Shuar community in Ecuador have been hosting tourists seeking retreats that feature traditional medicinal plants such as ayahuasca and tobacco. The community has provided individual ceremonies with the plants, or more complex rites such as Natemamu. Natemamu is a rite that is comprised of repetitive ceremonies lasting ten to twelve days, which involves drinking large quantities of Ayahuasca.

The author primarily focuses on: 1) the commodification of the Shuar $\mathrm{Na}$ temamu rite as a product that is offered on the global market; and 2) the impacts of this commercial trade on the hosts and visitors. This article is based on data collected by means of participant observation, interviews, and audio-visual documentations.

The findings imply that the introduction of western tourists to the Shuar community and its rites has contributed to processual changes to the rite and to ideational and material changes on both sides. Furthermore, the findings suggest that while the tourists experienced more ideational changes, the impact on Shuars was more material. This seems to be in accordance with the respective expectations of the encounter of both groups.
\end{abstract}

\section{Key words}

Ayahuasca, rite, commodification, tradition, ethno-tourism, exchange

\section{Acknowledgment}

I would like to thank all participants who cooperated with me during all stages of my research. I would also like to thank my supervisors, consultants and namely Cengiz Efe Okumus, who provided me with valuable insights and feedback related to my work.

This study was written with the support of the Ministry of Education, Youth and Sports, grant project IGA_FF_2019_023 (Advanced Research in Social Sciences, 2019) and with the support of the development programme 'International Student Mobility 2020' of The Ministry of Education, Youth and Sports, received by the Faculty of Arts of the Palacký University in Olomouc.

\section{Contact}

Mgr. Dima Salibová, Katedra sociologie, andragogiky a kulturní antropologie, Filozofická fakulta Univerzity Palackého v Olomouci, tř. Svobody 671/8, 77900 Olomouc, Czech Republic; e-mail: salibova.d@gmail.com.

\section{Jak citovat/ How to cite}

Salibová, Dima. (2020). Ayahuasca Ethno-tourism and its Impact on the Indigenous Shuar Community (Ecuador) and Western Participants. Český lid 107: 511-532. doi:http://dx.doi.org/10.21104/CL.2020.4.05 


\section{Introduction}

Among the general public, there may still be an association with isolated civilisations and "noble savages". However, indigenous groups are neither stuck in a timeless state, nor they are only driven by what a westerner might imagine to be "pure" ecological, selfless, or similar motives. The idea of the "ecological Indian" is connected to Euro-American discourses of self-criticism that can be traced back to 20 th century ecological movements, rather than to an accurate reflection of the indigenous reality (see Krech 1999).

In recent times, many indigenous people have begun to commercialise different aspects of their cultural heritage in pursuit of profit, including the Shuar, who entered the global market decades ago with offerings of traditional healing ceremonies using plants such as ayahuasca, datura, tobacco, and even more complex rituals.

In the context of ayahuasca globalisation, my aim was to investigate the (re)production of one of these complex rituals for foreign visitors - the Natemamu rite. I use the word (re)production, because the authenticity of so-called traditional rituals performed nowadays is difficult to evaluate, though the motivation to attend an authentic traditional ritual is common among tourists who travel to the area. The idea of authenticity evokes an image of existing, traditional, ancient and intact indigenous practices that have been resistant to change, which might stand for the opposite of spoilt modernity.

I conducted a total of three months of field work in 2019 and 2020 with the aim of answering the following questions:

1) How is Natemamu commercialised and offered as a commodity on the global market?

2) How is the rite conducted within the non-traditional setting that has emerged from global tourism?

3) What are the impacts of this encounter on both sides (for the hosts and the tourists)?

My research took place in the Morona Santiago region of Ecuador, in the vicinity of the Kupiamais River. The exact location and name of the village is not disclosed for reasons of confidentiality. During my field work, I lived with an indigenous Shuar family that offers Natemamu to domestic and foreign visitors.

Natemamu is a rite that is usually planned to last ten to twelve days and is composed of various ceremonies. The main ceremony within this rite is 
the drinking of large quantities of ayahuasca "tea". The generally expected effect of Natemamu, for both natives and tourists, is to induce a psychophysical purification. Its form goes beyond ordinary ayahuasca ceremonies in its intensity and the psychophysical demands it places on participants.

In the field study, I applied standard anthropological research tools such as participant observation, interviews and audio-visual recordings (see, for example, Bernard 2017). During my field work, I lived with locals and actively participated in the rite. With the aid of a Czech informant, who was an apprentice of the shaman and a trusted member of the local community, I interviewed thirteen Czech participants (before, during and after Natemamu), the natives, the shaman, and his assistants. All the interviews were audio recorded for evidence and further elaboration.

\section{Ethno-tourism}

The travelling of tourists to culturally foreign areas creates an opportunity for transactions that have transformative effects on the hosting and visiting groups (Nash 1996). Some authors have adopted the terminology of economics, perceiving tourism as a market space, whose effects on the parties are mediated by the visitors' willingness to travel and purchase and the hosts' willingness to produce and sell (Smith 2012). Konopíková and Soukup (2014) describe tourism as a social dynamic practice that includes transfers or exchanges of images, signs, symbols, powers, goods, services, money and people. The visitors are prone to change, but they also change the host community and contribute to modifications in local values and attitudes (Konopíková - Soukup 2014).

According to an OECD report (1994), tourism in the developed world has been on the increase since the nineteenth century, due to growing disposable incomes and the increasing number of paid holidays and education, which has embraced the desire to travel and explore both man-made and natural heritage. Improvements in international and urban-rural transport connections and the increasing possibilities for advertisement (e.g. travel agencies, media) have also helped this trend. Tourism can positively enhance economic growth by transferring capital to the areas visited. The visitors can also help insofar as: recognising the significance of local handcrafts and arts and purchasing them; creating job opportunities (in services, culture interpretation, transportation etc.); encouraging new construction; and funding conservation. This also leads to cultural and economic change in rural or non-industrial and countryside areas (OECD 1994).

Ethno-tourism is a form of tourism where the main goal of the tourist is to experience the host community and its traditions and cultural differences. 
This creates an opportunity for groups that possess this kind of cultural difference to promote and commercialise their ethnicity (on commodifying cultural difference, see Jackson 1999). This commercialised part of ethnicity usually includes indigenous traditions, which are supposed to have been passed down through generations (see, for example, Santa - Tiatco 2019).

Konopíková and Soukup (2014) assert that tourism can be seen as postcolonial behaviour, where vulnerable and less developed territories can be culturally dominated and where idealised past colonial images can be reapplied. Similarly, Taylor (2001) views the legacy of colonialism not only in terms of economic and political domination, but also in the production of stereotyped fantasies and images about indigenous peoples' nature, which shape the tourists expectations of the authenticity of those that they desire to encounter. Furthermore, as Schiller (2010) noted, the resources to travel are usually localised in developed rich states, which mirrors the colonial scheme. The ability to cross borders and the numerous obstacles within this process reflects the global power imbalance. Citizens of the states that dominate the world, militarily or economically, are usually able to travel to the rest of the world with fewer barriers (Schiller 2010). Some authors argue that ethno-tourism can sometimes take a form of pilgrimage. Konopíková and Soukup (2014) point out that a person travelling is evading the routine social structure and conventions by travelling to an unknown territory where one finds oneself a stranger among the local people. Travelling could therefore be experienced as a form of escape from daily routine, a release from the conformed order of situations and norms. Similarly, Wang (1999) adds that the liminality experienced in such forms of tourism can keep a distance from the constraints of everyday modern life (prescriptions, obligations, work ethic, etc.) and suspend routine order and norms. Turner (1974) argued that pilgrimage and the process of travelling and crossing the borders of distinct geographical areas and national borders potentially resembles rites of passage. Through travelling, the individual may enter a "liminoid"1 phase, which is between leaving one post and taking up another (Turner 1974).

Ayahuasca tourism can be considered an example of ethno-tourism. It is driven by the tourist's desire for an "authentic experience" of the ayahuasca ceremony, as it is traditionally practiced within ethnic groups, especially in Brazil, Colombia, Peru and Ecuador (see, for example, Tupper 2008).

Based on her field research in Iquitos in Peru, Fotiou (2016) stated that Ayahuasca tourism was similar to pilgrimage in the sense of healing and

1 Turner applied the term "liminoid" to the newly emerged settings in order to distinguish it from the "liminal" phase within indigenous tribal ritual practice (see Turner 1974). 
the personal transformation goals of the tourists. Shamanism has begun to be viewed as an archaic religious form connected with nature, and thus to be an alternative to modern technocratism. "Spiritual noble savages" are seen to be endowed with inner harmony (with oneself, endowed with wisdom) and outer harmony in relation to the environment, which offers inspiration for modern world problems. This has resulted in the idealisation of shamanic practices. This contemporary idealisation of shamanism has a connection to European romanticisms and American transcendentalisms and their vocalisations of interest in mysterious and spiritual aspects of living (Fotiou 2016).

Similarly, Dobkin de Rios and Rumrrill (2009) mentioned that westerners' desire to seek self-actualisation and self-transformation is often accompanied with dissatisfaction with values and identities offered by their cultures of origin, which drives the "drug tourism". The authors discuss the risks of this kind of tourism, such as falling into the lap of charlatans and shamans with no appropriate training and knowledge (a long apprenticeship is common for indigenous or mestizo traditional practices).

From a more critical point of view, Ethno-tourism and tourism to postcolonial countries can involve continuous post-colonial exploitation and cultural dominance over indigenous cultures. Thinking about world history against the background of imperial history, as suggested by Edward Said (1989), is important for understanding the unequal position of contemporary indigenous cultures in comparison with Occidental (including former colonial) cultures. Commercialising cultural heritage, which is usually referred to as a commodification (see, for example, Nash 2000; Dobkin de Rios - Rumrrill 2009; Stronza 2001), can be a result of the forced adaptation of native groups, who turn their cultural heritage into a commodity for sale because of their unfavourable economic conditions and the impossibility of maintaining their traditional way of life within the modern state. Critiques such as Norberg-Hodge (2000), with the example of the Ladakh culture, have demonstrated how indigenous economies that were sustainable for centuries have recently been replaced by the Western model, leading to consumerism, a market economy and modernisation. This has been triggered specifically by the presence of people from the outside world.

\section{Authenticity of traditions}

Ethno-tourism is often related to tourists' desire to receive an authentic experience associated with a particular indigenous practice or heritage. The concept of authenticity is an important attribute of such heritage tourism (Chhabra - Healy - Sills 2003). 
Many different approaches have been adopted to evaluate the authenticity of traditions. The original more historical objectivist approach evaluated authenticity through imagined connections to past local traditions (corresponding with temporal distance), which stood as the original true models to be reproduced (Wang 1999). These reproduced stereotyped images are used in the tourism industry to generate attraction for incomers. MacCannell $(1973 ; 1976)$ coined the term "staged authenticity" to define representation of culture as a sight object for tourism in the same way as museum expositions are. Taylor (2001) adds that staged authenticity is based on minimal direct contact or interaction with the natives. It is more distant, based on essentialism and stereotyped indigenous images and is well demonstrated with examples of staged shows, brochures, postcards, and other media representations. This contrasts with another form of encounter between natives and tourists that is based on direct interactional experiences and participation in rites or performances, which take place in a more natural environment, rather than in hotels or museums (Taylor 2001). Nevertheless, Chhabra, Healy and Sills (2003) observed that even staged events can still contain links to the past and symbols representing cultural identity, even if the performance has been modified. Furthermore, other authors argue that even staged authenticity does not necessarily exclude perceived authenticity in the experience of the participants.

Wang (1999), for example, noted that the concept of staged authenticity follows the objectivist discourse - the concept of authenticity of objective original, within which the tourist's experience cannot be counted as authentic even if they themselves experience it as authentic. On the other hand, the constructivist approach emphasises authenticity as a feeling. The same author described a concept of existential authenticity that could also be experienced through tourist activities. For example, participating in a traditional dance can generate feelings of freedom, spontaneity, and a connection with a purer and truer self, which can be attributed to primitive or pre-civilized forms of living.

From a more critical perspective, authenticity can be considered a label based on stereotyped expectations and images attached to the other cultures by the tourist's home society. The objects of tourism or others are experienced as authentic not because they are originals or reality, but because they are perceived as signs of (constructed and projected) authenticity (see, for example, Wang 1999). This could also be associated with the exoticisation of the natives, through the idea of the absent development and present "timelessness" in which these cultures might be expected to exist (Wang 1999). Taylor (2001) noted that the narrative of authenticity based on pure, naturally, spiritually, and culturally "unspoilt" primitives produced by 
western culture is based on a "tragic" experience of modernity, progress, mass culture, industrialization and technology, along with alienation from nature and accompanied by fragmentation and loss (the inauthentic "plastic" world of the consumer). With regard to tourist advertising, the tourist may believe they can (re)discover through the particular advertised experience a lost authentic and primitive self (Taylor 2001).

I would like to conclude this section with a few notes on the natives' perspectives and evaluations of their own traditions.

Several authors have discussed the problem of authenticity and its perception by natives. They usually conclude that today's traditions can be considered hybrid, taking into account that they are not static but evolve in historical change and arise from mutually constituting discourses of tradition and modernity.

Natives in these particular cases (see Johnson 2008; Selka 2007; Sorensen 2018) seemed to judge their own traditions as legitimate based on how meaningfully these traditions reconstructed their cultural identity under new circumstances (for example, within mutually constitutive localised and globalised announcements of indigenous identity), and how the traditions reconfigured themselves upon purported links to the (remembered) past.

The cultural identity and the traditions are made up in a symbolic process, therefore they cannot be perceived as static. They constantly reinterpret past symbols into new discourses and creatively manage historical ruptures that intrude into the tradition's continuity. For analytical purposes, it is possible to distinguish units within a rite's evaluation, such as its process and performance, symbols/ discourses/ narratives, and material artefacts.

Stephen Selka (2007), in particular, illustrated how modernisation brought innovations to the conduct of a tradition with the Afro-Brazilian rite Candomblé. The rite has recently become condensed to its most necessary core elements when compared to the past, due to the fact that modern people lack the time to relax, observe and leave street life behind. The religion itself reflected the rapid pace of modern living, for example, the initiation periods of initiates have been abbreviated, which some locals metaphorically compared to fast food production.

Contemporary locals judged the credibility and authenticity of the rite based on how and where the practitioners were trained and how convincing they were in presenting themselves as persons who held the secrets thus reinforcing the mysticism of the religion. Nevertheless, the tradition was seen as flexible especially among urban and young practitioners of this rite. The technologies changed and a new middle-class white group of candidates emerged. Some of the changes did not seem to disrupt the perceived integrity of the religious practices, such as cooking on a cooker instead of more 
traditional firewood and practising in modern buildings instead of temples. However, some of the changes were viewed as threatening, such as recordings of sacred rites. Nevertheless, even the recordings were sometimes encouraged if they promised to bring more publicity, money, and an aura of modernity to the event. Thus, the discourse of traditionalism coexisted with a desire for an aura of modernity. In addition, modernising the tradition could also arise as a result of local people's need to succeed in an emerging consumer society (Selka 2007).

\section{The Shuar and the Natemamu rite}

In this section I will briefly introduce the Shuar culture with special emphasis on their religious practices. The territory traditionally inhabited by the indigenous Shuar communities of South America extends through south-eastern Ecuador and western Peru within the Amazon basin (Bennett et al. 2002; Harner 1972). In the last census of the indigenous population in Ecuador, from 2010 (data retrieved from Instituto nacional de estadística y censos), the Shuar numbered nearly 80,000 individuals. The Shuar were generally known for their warrior spirit and stubbornness. After all, they were the only regional indigenous group that was never conquered by the Spanish invaders, although they maintained business contact with the Spaniards and later engaged in wage labour (see, for example, Harner 1972; Rubenstein 2001).

The most significant means of the Shuar rites (including Natemamu) and ceremonies were the psychoactive plants ayahuasca (official botanical terminology: Banisteriopsis caapi), tobacco (Nicotiana tabacum) and datura (Brugmansia suaveolens; Bennett et al. 2002), and in recent years, as a result of globalisation and substantial exports, the use of particularly ayahuasca has spread considerably to areas of the Western world, because of its spiritual, healing and psychotherapeutic effects (see, for example, Fotiou 2016; Trichter 2010).

Ayahuasca (see Figure 1) is a Quechuan name for the vine Banisteriopsis caapi, but also for a hallucinogenic beverage, and in indigenous circles it is considered to be a "medicine". Its use has been traditionally associated with the states of Brazil, Peru, Colombia and Ecuador (dos Santos et al. 2016a). The vine is used to prepare a drink, to which more plants can be added (but not necessarily), such as Psychotria viridis (mostly known by its Quechua name Chacruna, in Shuar Yagê) containing dimethyltryptamine (DMT; dos Santos et al. 2016b). DMT is a naturally occurring hallucinogenic molecule (DMT, 2019), and is sometimes not added to the beverage, which has then rather a purgative effect (Horák 2019). However, as reported by Harner (1972) and as I can attest from my ethnographic observation of 


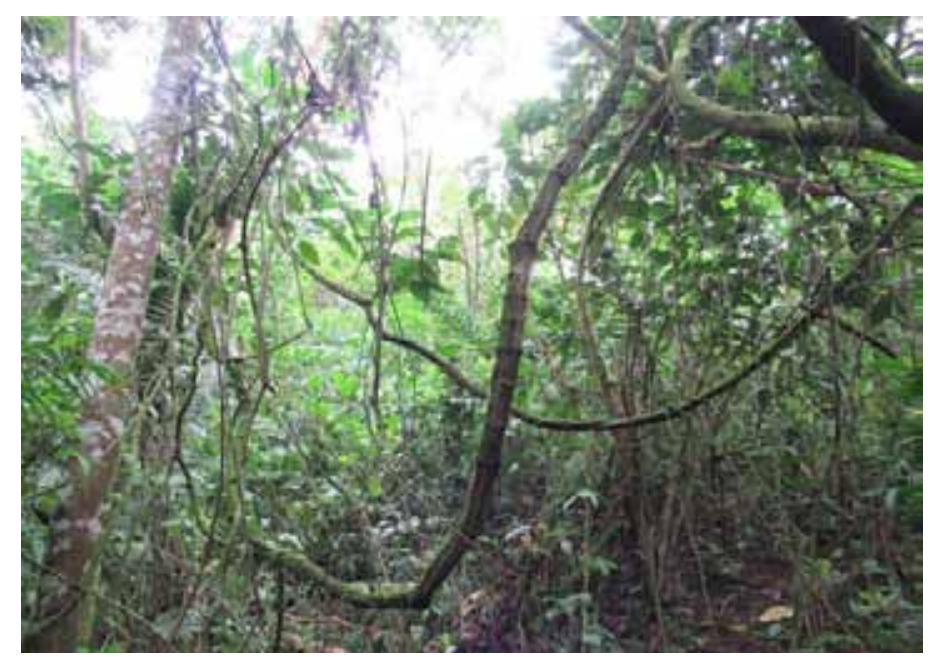

Figure 1 An ayahuasca vine cultivated in a Shuar family garden. Photo: Author

ayahuasca usage in Natemamu, a strong hallucinogenic effect still occurs if a person is given a sufficient quantity of the drink.

The anthropologist Luna (2011) emphasised that traditional use of the medicinal plants can be understood only in the context of the original tribal spirituality and their beliefs in an all-pervasive spiritual aspect uniting the seen and the unseen. The plants were considered to be beings and teachers, and in order to communicate with them, especially through emerging visions, one needed to follow nutritional and sexual restrictions to ensure proper cleansing, which was the essential condition of a well-established contact with the plants (Luna 2011). Harner (1972) in his classical ethnography The fivaro: People of sacred waterfalls, described precisely the Shuar beliefs in hidden forces, accessible by means of hallucinogens. These forces were to be viewed as the real determinants of life and death. Explanations about causality were derived only through entering the supernatural (real) world. It was believed that what was happening in the supernatural world would later be manifested in the world of everyday life.

The Shuar ceremonies and rites were traditionally and are still today led by an Uwishin (Figure 2), who is meant to be "someone who knows all the secrets" (Pratt 2007); or, as the local Shuar expressed it, "the knowing one". An Uroishin is someone we usually call a shaman. However, this is a western use of the originally north Asian, probably Tungusian, term saman, šaman, or xaman (Mongol: šaman, Turkish: kam, xam) for a different region (for the etymology of the word shaman, see Laufer 1917). It has been noted by various authors that this use is also associated with the problematic stereotyping of a shaman's image, for example, its idealisation and promotion 
as a universal practice regardless of its cultural and temporal context (on stereotypes, see, for example, Wernitznig 2003; Fotiou 2016).

One of the rites said by the Shuar to be an ancient practice is Natemamu. This is usually a ten to twelve day long cycle of distinct ceremonies with various psychoactive plants that are traditionally used in Shuar culture. The meaning of the word Natemamu seems to be fuzzy. According to the Shuar-Catalan dictionary it can be translated as the rite in which the Natem is taken (from Spanish: tomar la medicina natem, rito en el cual se toma el Natem; Pellizzaro - Náwech 2005). I was told by the Shuar that it basically means "a shower with Natem".

Along with the ordinary drinking of small amounts of concentrated ayahuasca beverage, the whole rite also includes: Tunakaramamu, i.e, a march through the jungle and waterfall bathing; Tsankmamu, i.e., the drinking of leached fermented or fresh tobacco juice; and four days of Natemamu, i.e., the drinking of ayahuasca tea without additive plants, which can amount to several litres per day and is based mainly on "purgas", which is a local term for physical detoxification characterised by vomiting and diarrhoea after ayahuasca usage and accompanied by emotional release and catharsis. Purgas are considered to be the desired effect of the usage (see, for example, Mabit 2007; Bouso - Riba 2014).

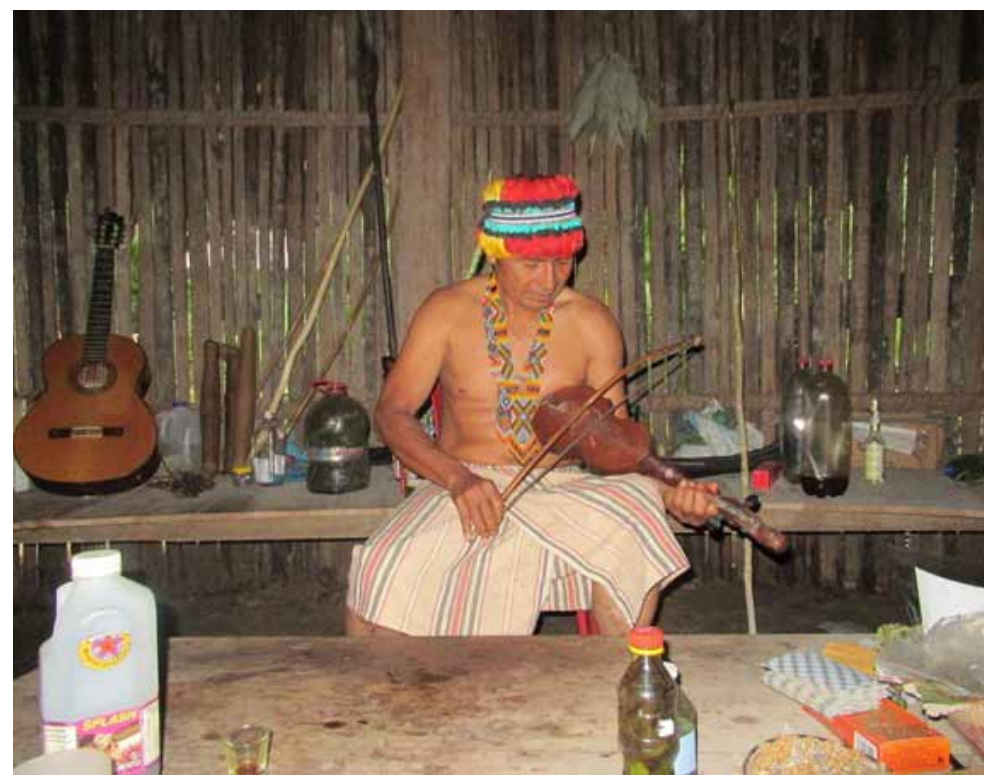

Figure 2 An Uwishin plays the "kaer", a traditional instrument in the ceremony. Photo: Author 
The whole rite goes beyond ordinary ayahuasca ceremonies in its intensity and, for some people, it can be an extreme experience with transformative potential. It is a physically and psychically challenging ritual, which is today available to international participants. According to Shuar beliefs, the whole ritual process helps to harmonize the life of an individual through deep physical purification, emotional catharsis, receiving insights and connection with the essence of life.

\section{The exchange between encountering groups}

My investigation took place in a Shuar community which inhabits the shore of the Kupiamais River in the Morona Santiago region of Ecuador. The village is situated at the edge of the Amazon rainforest, close to the town of Gualaquiza. The local family promoted itself through social media and an internet website, with an email address for further inquiries into the healing procedures on offer. A response with details of the rites and pricing was received after a few days, but, interestingly, the social media site was managed by people outside the family, who were mainly western co-workers of the Uwishin. The Uwishin is the "shaman" and the head of the family. The official price of the ten-day Natemamu rite in 2019 and 2020 was 1200 USD, but, in practice, the pricing varied from one participant to another, depending on their relation to the family and their ability to offer benefits beside monetary ones.

The second way of becoming a participant in local ceremonial offers, was to be a member of the western neo-shaman network group, who, at the same time, are usually the Uwishin's apprentices and who promote the particular indigenous family in their own countries of origin. Through this process, they were usually able to get together a group of candidates for the Natemamu rite.

The Natemamu rite in both cases (people contacting the family directly through social media or being part of an organised group around a neoshaman) was each time conducted in close cooperation with the external neo-shamans, who took on the role of co-organisers of the rite. They were asked to be the initial contact persons for the candidates and to help maintain the coherence of the group during the rite, which included giving practical support and translating for those participants who did not speak Spanish (the official language spoken by the Uwishin). The prices of the rite and each ceremony have been increasing for the past decade to finance the family's investments in facilities and infrastructure and to compensate for increasing costs of living. Despite the fact that locals still turn to the Uwishin for help with curing illnesses, the income generated from western visitors is 
of crucial importance to the Shuar family. The tourists usually come from wealthier countries, and therefore can afford to pay the higher prices. The price of each ayahuasca ceremony during my stay was 50 USD per person per night, which is closer to European standards, but still far lower.

The tourism, as mentioned earlier (see the section on ethno-tourism), ignites an exchange between visitors and locals on multiple levels. One would expect that as the tourism became a significant source of income for the community, the tradition and lifestyle of the local family would change in comparison with the past, when the source of goods was based mainly on the exploitation of natural resources and, later, on a wage labour. My observations and interviews with long term foreign participants in the rites support the claims that as visitors started arriving in the indigenous area, the area started to change. For example, the Shuar family invested resources in improving the residency, built new and advanced facilities such as a guest house (Figure 3), toilets and showers, a Wi-Fi connection in a locality where there is not even a phone signal and so on. Visitors not only pay to participate in the ceremonies, but they also purchase local bracelets and jewellery (made from glass beads and fruit seeds), which provides an opportunity to earn money for those members of the family who do not directly participate in the organisation of the rite.

Many of the changes in the village were originally facilitated and implemented by the non-indigenous co-organisers in order to make the environment more suitable for the incoming westerners. These changes have improved the living standards of both the locals and the incomers.

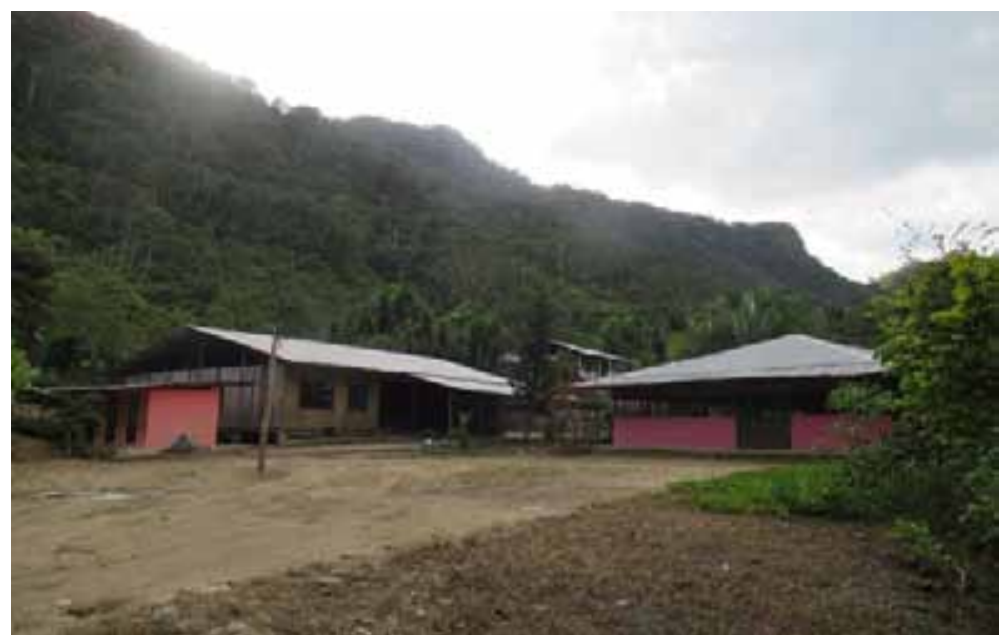

Figure 3 New facilities in the village. The guest house is on the left. Various utility building (for storage, a kitchen) is on the right. Photo: Author 
During my 2020 stay, I witnessed the visitors coordinating their labour to build a solid pathway to the ceremonial building (Figure 4), helping cultivate the river shore, and preparing a space for the sweat room, which they also later built using bamboo canes. The visitors who had contributed to the construction work were later given a discount for the Natemamu. This was the outcome of a deal with the Uwishin negotiated by a neo-shaman. The discounts were also given to those who had helped in the kitchen and cooked for the participants throughout the programme.

The willingness to accept these overtures to make changes in the personal space of the community, mostly depended, according to my understanding, on the relationship and level of trust between the Uwishin (the head of the community) and the co-organisers, otherwise it might have been viewed as unwanted penetration into the family's personal space. Instead, it was accepted as an improvement that could increase their attractiveness and perhaps improve their position in the competitive global tourist industry.

Apart from the material exchange, the tourism ignited an ideational (ex)change, with visible impacts on the visitor groups. This willingness for change can be better understood when one considers the motivation behind travelling to the area. In the interviews with the visitors, an array of topics emerged in relation to their motivation to leave their home countries and travel to this part of the Amazon. Among them was a desire to experience authentic shamanic guidance and healing and the intensive ayahuasca experience. One participant told me:

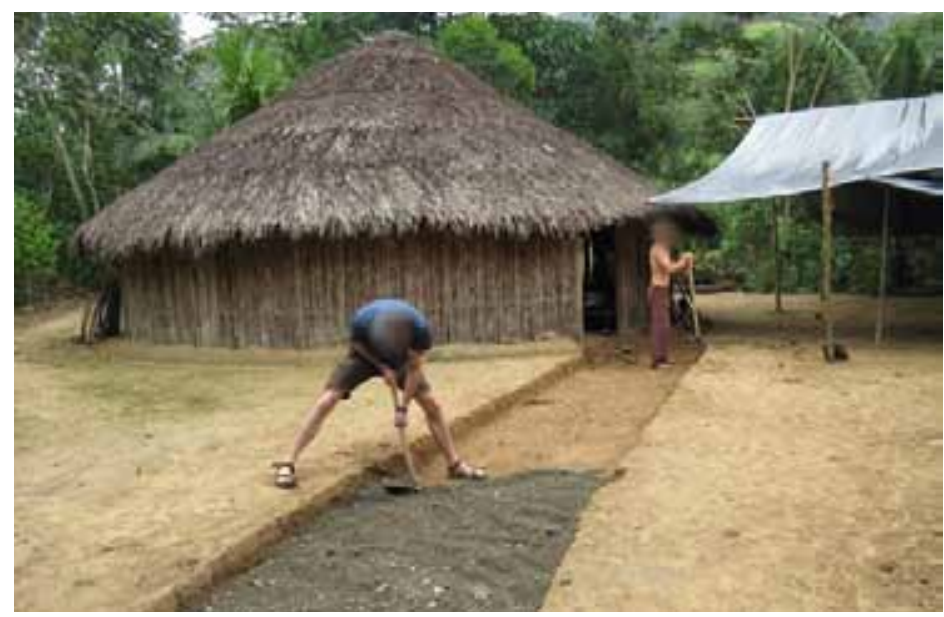

Figure 4 Construction work in the village done by Czech Natemamu participants. In the background is the traditional oval building used for ceremonial purposes. Photo: Author 
"I heard about Natemamu from Mr. X, and I really am a "catharsis" person. In the ceremonies, I go for three shots of ayahuasca (author's note: the ordinary amount is one), but twelve days, that would be awesome."

Others expressed a desire to receive new knowledge, insights, and visions to improve their lives, to evolve psycho-spiritually, and to reconnect with nature and a "simple" way of life, as opposed to a modern stressful lifestyle. This could have been supported and even mediated by the act of leaving the home country and putting oneself into a new context, resembling the liminal phase of rites of passage, as described by Turner and others (see the section on ethno-tourism). The following statement of a participant is very illustrative:

"For me it's all about attention and conscious work (with ayahuasca), we came because of this, because here it's much easier, the nature here resonates so strongly. I also don't have any emails here, no SMSs, I cut it all off, and I left all my responsibilities behind me. So it is really, in some sense, very pure here. I can concentrate on myself and concentrate on the way the medicine will lead me."

The visitors came to "learn from the indigenous inhabitants". What they often appreciated was the simplicity of local rural life. The Uwishin continuously emphasized attitudes such as acceptance, love and tranquillity, which was seen as inspirational by many of the interviewed people. These attitudes seemed to be crucial in the proper use of the plants and the management of the resulting physical and psychological states. Some of the visitors also internalized elements of indigenous cosmological beliefs in supernatural energies and entities, in the cosmic plan and life's purpose. Most of the tourists stated that they left the place with a sense of fulfilment and enrichment.

It appeared that the visitors evaluated the indigenous beliefs as pure, honest, healthy, and so on. This could partly be the result of a misleading positive stereotyping of the indigenous image, lifestyle and characteristics (see the above section on ethno-tourism), especially obvious in cases where the indigenous reality led to disappointment. The stereotyping can be expressed, for example, in the idea of indigenous inner and outer harmony or their non-profit or altruistic motives.

Paradoxically, despite the stereotyped image of ecological natives, I witnessed that it was the foreign visitors who emphasised the use of ecological detergents, proper waste separation and so on (perhaps this is more typical for wealthier countries in general). The Shuar form of waste "management" in some cases included disposing of waste in the forest. Another example 
was that the Shuars used plastic to light fires, as it was simply more practical in an area where daily rains and high humidity worsen the conditions for making an open fire.

Moreover, the idea of the non-profit nature of the indigenous inhabitants was challenged in the eyes of some visitors, as nothing came free of charge and some of the goods that the natives offered exceeded average Ecuadorian prices. In relation to this, sometimes the natives were suspected of taking advantage of the visitors. One of the participants perceived the Urwishin as follows:

"I think the Shaman's role is to cure people. He is a healer to me. In the last sessions (author's note: after Natemamu), I had a horrible vision and told him I didn't want to leave in this state. With those feelings I had, he didn't comfort me, he didn't say - 'you can make it, I believe in you, if you want I can give you further treatment' - as I would expect from a shaman. He didn't say 'I will explain the visions you saw', as he did previously. He did it when he was paid for it, but when I needed help, he didn't help. It took away my belief in all of this. I have a feeling that this is all about money." (Author's note: this happened during the final ceremonies after the official Natemamu programme. The Uwishin did not charge extra for these ceremonies.)

And, elsewhere, the same participant noted:

"I bought the handicrafts from the family, because the co-organiser told us that it would help them, even though the same things were much cheaper in the market downtown (also sold by indigenous people)."

When I asked, the members of the indigenous family displayed an awareness of a cultural specificity of the western visitors. Sometimes they commented on it in an ironic way (for example, targeting our "obsession with documents and papers"). It did not seem as if that they evaluated western beliefs as in some way beneficial for their lives, and when I asked the Uwishin, if they recognized any differences between "the western participants and the local indigenous people" I was told precisely that they have difficulties with our "unconsciousness and unawareness" and that we come in an "unconscious state". As the Urwishin said:

"There's a big difference. We try to find the best way to give an example to make it possible for them to understand, but it's very challenging, because they come in an unconscious state. They have strong egos and it makes it difficult..." 
In another interview he explained what the ego is:

"It arises from the dark pole, it's a form of darkness, for example, hatred, envy etc. If there was not the world of darkness, there would not be the ego, but it has an important role in the balance of life."

Returning to the topic of changes associated with modernity, with more of a focus on the conduct of the rite, some elements are obvious simply because they reflect the technological advancements of the current age. For example, there were material elements such as the installation of electric bulbs in the ceremonial building - a building that nevertheless retained its traditional oval shape and traditional construction materials, such as palm wood and leaves. Sometimes gas cookers were used for preparing ayahuasca in Natemamu, but, during the four days of intense ayahuasca tea drinking, it was replaced with a more traditional means of preparation - above an open fire in the oval Cabaña ceremonial building.

Another feature was the Wi-Fi connection in the place, which appeared to have the potential to disrupt the ritual's integrity. It was strongly recommended that we avoid using the connection for the whole period of Natemamu, because it was said that contact with the outside world (especially with other people) could possibly disrupt the processes one went through on a personal level, and could cause distress or harm, especially if it weakened the participant's concentration (it was said that "it could take us back"). Other material changes included using plastic bottles to store the beverages of sacred plants, and even wearing football jerseys on a march to a "sacred" waterfall.

There were also some processual changes in the conduct of the rite (as described by the natives), some of which were implemented as a response to the demands on and the psychophysical abilities of tourists, for example, the march through the jungle was shortened over time, a less extreme diet was required, and the amount of Natem drunk was left up to participants themselves.

During the programme, the participants were also introduced to medicinal plants outside the traditional use of the Shuar, such as the psychoactive cactus San Pedro or coca, which are both more typical for Andean traditional medicine (on San Pedro, see Ogunbodede et al 2010; on coca, see Biondich - Joslin 2016). Similarly, the involvement of the "sweat room" originated in North America, according to its practitioners.

Another phenomenon that emerged with modernity was the possibility to use audio-visual devices in the ceremonies. As globalisation has established a way to introduce traditional practices to the West, westerners have become interested in exploring them in their original indigenous settings. When 
I was present at the location in January 2020, a documentary maker from Germany came to investigate the use of the medicines by the local "shaman", as the rites conducted in western countries may differ significantly. They used recording tools, a camera, and microphone during the actual ceremonies. This was seen as intrusive by many of the participants I spoke with, although the Urishin himself was open to it and was willing to introduce the traditional practice on camera. Some of the participants refused to participate in the ceremony when the recording technology was present, and some of them participated, but then later told me, that they perceived it either as a representation of "westerners' disrespect for the sacred", or as the "westerners' need to capture everything with modern tools", which can also be interpreted as the opposite of the rural living simplicity that they had come to seek. One of the participants told me:

"I think some things should stay unrevealed or unexposed. It was okay for me that he records us around (in everyday activities), but the rite itself does not belong on television, because it's really untransferable... I see in this our hunger to document everything, write everything down, record it and, in the best case, put it on YouTube. This is the plague of this world."

I personally was uncomfortable with the fact that someone had come to record the session I participated in, as I experienced it as disrespectful to the very intimate ritual process.

Interestingly, when I asked the Uwishin if he had observed any changes to the conduct of the rite over the course of time, he denied it, even though an impartial observer would object, due to the obvious changes. However, his standpoint can be interpreted as being concerned with the presence and purpose of the core elements, in the sense that the jungle march, and drinking tobacco and ayahuasca tea had not changed. This brings us to questions about authenticity noted earlier regarding the authenticity of traditions. Since the rite is being offered as a commodity, such claims with regard to its intact character can be also interpreted as a part of the commercialisation strategy. But it is important to emphasise that the plants still have an important role in the natives' beliefs associated with life's order and the order of the supernatural world, the treatment of illness and so on. Not only do they offer the plants to visitors, but they also occasionally imbibe the medicinal plants, especially when illnesses or accidents occur, or if they aspire to become the Uwishin.

Finally, I would like to draw attention to my observation of the Uwishin's changing role in the new setting, arising from the global tourism. As 
requests from locals and foreign visitors differed, so did the Uwishin's approach to accommodating the different needs. During the rites and certain ceremonies of Natemamu, the Uwishin accepted visits from local people who approached him for healing purposes. Making use of such services is an ordinary part of local culture and common practice. Local people did not come in order to receive spiritual awakening or psychological insights, as is the case with the western visitors.

In earlier literature about shamanism (for example, Eliade 2004) there was a distinction between the shaman's role of a healer and priest (for example, when leading and coordinating rites and ceremonies), held by him on different occasions. The Uwishin also had the role of healer, especially concerning diseases believed to be caused by dark magic. In these cases, he is the one who imbibes the medicinal plants and then applies the treatment, for example, by traditional methods such as sucking the body parts of the inflicted person and spitting out.

The role of the Uwishin in ayahuasca ceremonies that are held for tourists differed from his role for the locals. He was still the one who kept the structure of the rite, and intervened, if necessary, (with his healing powers), but, on these occasions, the visitors took the medicinal plants too. In this context, the Uwishin himself mentioned that he is the one who can show the participants the path of the proper use of the plants, because he has already been down this path. Sometimes he referred to himself in this context as a "master". From this statement, it can be said that his role resembled that of a mentor, who instructs the less experienced in the particular mastery and accompanies the participants on their way through the process of using the plants. However, the mastery is given not only by experience, but also by the right attitudes. During the ceremonies, he often emphasised the most important principles needed for the correct use of the plants, so that the benefits could be maximised and the harms reduced. I see differences between the formerly assigned roles of healer or priest to the shaman, and the newly emergent role of shaman as "mentor". While the former usually provides direct instructions for participants to follow so that they can find resolution for their issues, the latter aims to provide insight and educate the participant about the techniques of shamanic expertise as well.

\section{Conclusion}

The Shuar community mentioned in this article has become increasingly popular with foreign tourists seeking traditional retreats with medicinal plants, of which ayahuasca is the most popular, alongside tobacco and datura. The community provides these medicinal plants during individual ceremonies 
or more complex rites such as Natemamu. Natemamu is ten to twelve days long and is comprised of a cycle of ceremonies that include drinking large amounts of ayahuasca beverage. The natives believe that participation in this rite should induce a psychophysical purification for the partaker.

The introduction of these ceremonies to western visitors has contributed to material, ideational and processual changes in both natives and tourists. These changes do not appear to have been equally distributed between natives and tourists. This phenomenon can be potentially explained by the respective motives and expectations of each group. The village of this particular Shuar community has undergone significant material changes partly to accommodate the living standards of western tourists, such as investments in new buildings, infrastructure and ceremonial sites, which has also consequently improved the natives' living conditions.

The Shuar community has introduced processual changes to the ceremonies, such as: i) decreasing the usual amount of beverage consumed during the ceremonies to accommodate the varying levels of physical and psychological endurance of tourists; ii) using modern tools for the ceremonies for practical reasons (for example, gas stoves and plastic bottles); and iii) introducing a recently emerged role of the Uwishin to the ceremonies, which was done to mentor the tourists during the ceremonies.

Based on my observations, the natives seemed eager to incorporate material goods and modern living elements (such as Wi-Fi internet), since it improved the living conditions for not just the tourists but also for themselves. Compared to the changes that the Shuar community had undergone, the visitors seemed eager to undergo ideational changes through internalising some of the indigenous people's beliefs. This is supported by the tourists' motives for travelling to the destination and participating in the rites, which are perceived as traditional. Based on the interviews, the tourists are seeking to obtain wisdom and experience visions that will improve their lives on a physical, psychological and spiritual level. For most of them, these expectations were more than fulfilled by the end of the programme. In some cases, the idealisation of shamanic practices by westerners led to their disappointment once they encountered the indigenous reality. This was mainly driven by their false expectations associated with imagined "proper" indigenous behaviours or attitudes based on the noble savage stereotype.

Despite many obvious changes to the conduct of the rite and the conditions, ayahuasca, datura and tobacco are still an integral part of Shuar lives. Consumption of these has evident links to past traditions and this consumption by community members still continues on special occasions. Part of this old tradition was fluidly transformed to meet the needs of 
a newly emergent group of participants, i.e., foreign visitors, in exchange for various benefits it provides for the natives.

October 2020

\section{Bibliography}

Bennett, Bradley - Baker, Marc - Andrade, Patricia. 2002. Ethnobotany of the Shuar of Eastern Ecuador. Advances in Economic Botany 14. New York: New York Botanical Garden Press: 1-299.

Bernard, H. Russell. 2017. Research methods in anthropology: Qualitative and quantitative approaches. Lanham: Rowman \& Littlefield.

Biondich, Amy - Joslin, Jeremy. 2016. Coca: the history and medical significance of an ancient Andean tradition. Emergency medicine international: $1-15$.

Bouso, José - Riba, Jordi. 2014. Ayahuasca and the Treatment of Drug Addiction. In: The Therapeutic Use of Ayahuasca. Berlin - Heidelberg: Springer Berlin Heidelberg: 95-109.

Dobkin de Rios, Marlene - Rumrrill, Róger. 2009. A hallucinogenic tea, laced with controversy. Ayahuasca in the Amazon and the United States. Westport: Praeger Publisher.

Dos Santos, Rafael - Balthazar, Fernanda - Bouso, José - Hallak, Jaime. 2016a. The current state of research on ayahuasca: a systematic review of human studies assessing psychiatric symptoms, neuropsychological functioning, and neuroimaging. Fournal of Psychopharmacology 30, 12: 1230-1247.

Dos Santos, Rafael - Osório, Flávia - Crippa, José - Hallak, Jaime. 2016b. Antidepressive and anxiolytic effects of ayahuasca: a systematic literature review of animal and human studies. Revista Brasileira de Psiquiatria 38, 1: 65-72.

DMT Hallucinogen. 2019. In: Encyclopaedia Britannica [online]. [2019-10-01]. Retrieved from: https://www.britannica.com/science/DMT

Eliade, Mircea. 2004. Shamanism: Archaic techniques of ecstasy. Princeton: Princeton University Press.

Fotiou, Evgenia. 2016. The Globalization of Ayahuasca Shamanism and the Erasure of Indigenous Shamanism. Anthropology of Consciousness 27, 2: 151-179.

Harner, Michael. 1972. The fivaro, people of the sacred waterfalls. Garden City, N.Y.: Published for the American Museum of Natural History [by] Doubleday/Natural History. 
Horák, Miroslav. 2019. Ayahuasca in the Czech Republic. Brno: Mendel University in Brno.

Instituto nacional de estadística y censos. 2010 [online]. Demografia Indigenas. [2019-10-01]. Retrieved from: https://www.ecuadorencifras. gob.ec/wp-content/descargas/Libros/Demografia/indigenas.pdf

Chhabra, Deepak - Healy, Robert - Sills, Erin. 2003. Staged authenticity and heritage tourism. Annals of tourism research 30, 3: 702-719.

Jackson, Peter. 1999. Commodity cultures: the traffic in things. Transactions of the institute of British Geographers 24, 1: 95-108.

Johnson, Greg. 2008. Authenticity, invention, articulation: Theorizing contemporary Hawaiian traditions from the outside. Method \& Theory in the Study of Religion 20, 3: 243-258.

Konopíková, Michaela - Soukup, Martin. 2014. Anthropology of Tourism: From Morocco to Papua New Guinea. Anthropologia Integra 5, 2: 35-47. Krech, Shepard. 1999. The ecological Indian: Myth and history. New York: WW Norton \& Company.

Laufer, Berthold. 1917. Origin of the Word Shaman. American Anthropologist 19, 3: 361-371.

Luna, Luis. 2011. Indigenous and mestizo use of ayahuasca: an overview. In: Dos Santos, Rafael (ed.): The Ethnopharmacology of Ayahuasca. Kerala: Transworld Research Network: 1-22.

Mabit, Jacques. 2007. Ayahuasca in the treatment of addictions. Psychedelic medicine: New evidence for hallucinogenic substances as treatments 2: 87-105.

MacCannell, Dean. 1973. Staged authenticity: Arrangements of social space in tourist settings. American journal of Sociology 79, 3: 589-603.

MacCannell, Dean. 1976. The tourist: a new theory of the new leisure class. New York: Schochel Books.

Nash, Dennison. 1996. Anthropology of tourism. Oxford: Pergamon.

Nash, June. 2000. Global integration and the commodification of culture. Ethnology 39, 2: 129-131.

Norberg-Hodge, Helena. 2000. Ancient futures: learning from Ladakh. London: Random House.

OECD. 1994. Tourism strategies and rural development. Paris: Organisation for economic cooperation and development.

Ogunbodede, Olabode - McCombs, Douglas - Trout, Keeper - Daley, Paul - Terry, Martin. 2010. New mescaline concentrations from 14 taxa/ cultivars of Echinopsis spp. (Cactaceae) ("San Pedro") and their relevance to shamanic practice. Fournal of ethnopharmacology 131, 2: 356-362.

Pellizzaro, Siro - Náwech, Fausto. 2005. Chicham: diccionario shuar-castellano. Quito: Abya Yala. 
Pratt, Christina. 2007. An encyclopedia of shamanism. Vol. 2. New York: Rosen Pub. Group.

Rubenstein, Steven. 2001. Colonialism, the Shuar Federation, and the Ecuadorian state. Environment and planning D: Society and Space 19, 3: 263-293.

Said, Edward. 1989. Representing the colonized: Anthropology's interlocutors. Critical inquiry 15, 2: 205-225.

Santa, Edieser - Tiatco, Anril. 2019. Tourism, heritage and cultural performance: Developing a modality of heritage tourism. Tourism Management Perspectives 31: 301-309.

Selka, Stephen. 2007. Mediated Authenticity: Tradition, Modernity, and Postmodernity in Brazilian Candombléé. Nova Religio: the Journal of Alternative and Emergent Religions 11, 1: 5-30.

Schiller, Nina. 2010. A global perspective on transnational migration: Theorising migration without methodological nationalism. In: Bauböck, Rainer - Faist, Thomas (eds.): Diaspora and transnationalism: concepts, theories and methods. Amsterdam: Amsterdam University Press.

Smith, Valene (ed.). 2012. Hosts and guests: The anthropology of tourism. Philadephia: University of Pennsylvania Press.

Sorensen, Clark. 2018. Worshiping the Goddesses of P'albong Mountain: Regional Variation, Authenticity, and Tradition. Acta Koreana 21, 2: 371-394.

Stronza, Amanda. 2001. Anthropology of tourism: Forging new ground for ecotourism and other alternatives. Annual review of anthropology 30, 1: 261-283.

Taylor, John. P. 2001. Authenticity and sincerity in tourism. Annals of tourism research 28, 1: 7-26.

Trichter, Stephen. 2010. Ayahuasca beyond the Amazon: the benefits and risks of a spreading tradition. Journal of Transpersonal Psychology 42, 2: 131-148.

Tupper, Kenneth. 2008. The globalization of ayahuasca: Harm reduction or benefit maximization? International Journal of Drug Policy 19, 4: 297-303.

Turner, Victor. 1974. Liminal to liminoid, in play, flow, and ritual: an essay in comparative symbology. Rice Institute Pamphlet-Rice University Studies 60, 3: 53-92.

Wang, Ning. 1999. Rethinking authenticity in tourism experience. Annals of tourism research 26, 2: 349-370.

Wernitznig, Dagmar. 2003. Going native or going naive? White shamanism and the neo-noble savage. Lanham, Md.: University Press of America. 